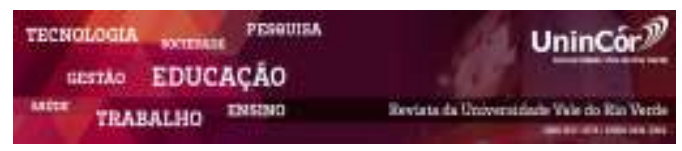

Revista da Universidade Vale do Rio Verde ISSN: 1517-0276 / EISSN: 2236-5362 Vol. 16 | n. 1 | Ano 2018

Domynique Roberta de Oliveira Esposito Discente da Graduação em Psicologia da UninCor domyniqueEsposito@hotmail.com

Thayse Figueira Guimarães Docente do programa de Mestrado em Letras da UninCor thayse.guimaraes@unincor.edu.br.

\section{ATIVISMO CONTRA VIOLÊNCIA DE GÊNERO NO CIBERESPAÇO}

\section{RESUMO}

Este artigo tem como propósito apresentar parte da pesquisa de caráter etnográfico desenvolvida no projeto da Iniciação Cientifica do Programa de Mestrado em Letras da Universidade Vale do Rio Verde-UninCor. Na pesquisa realizada, examinou-se relatos de violência de gênero, produzidos por mulheres no carnaval de 2017 e que circularam na Internet. O corpus da pesquisa foi composto por denúncias feitas por mulheres no Facebook entre os dias 18 de fevereiro e 05 de março de 2017. Neste estudo, o trabalho em análise focalizou o post de uma jovem, que relata um ato de violência e assedio sofrido por ela em um bloco de carnaval em São Paulo. Na análise, observou-se como a internauta, ao denunciar o ato de violência na rede e ao responder aos comentários de sua publicação, constrói-se como uma mulher vítima, mas empoderada, atuante no ativismo contra a violência de gênero na rede. Os dados contrariam a ideia de que a violência contra mulher deve ficar restrita ao foro privado, não aparecendo em um debate público e político. Tomamos a tecnologia como prática de ação sociopolítica (Moita Lopes, 2010), por meio da qual sub-políticas aparecem como linhas de fuga da política tradicional, fazendo circular alternativas às práticas e ideias fundamentalistas.

Palavras-chave: Violência contra mulher. Ciberativismo. Web 2.0. Ativismo de gênero.

\section{ACTIVISM AGAINST GENDERED VIOLENCE IN THE CIBERSPACE}

\begin{abstract}
The purpose of this paper is to present part of the ethnographical research developed in the scientific initiation of master of Letters Program at Unincor. In the research were examined gendered violence narratives, told by women during the 2017 Carnival, that circulated on the Internet. The corpus of the research was composed by denouncements made by women on Facebook between February $18^{\text {th }}$ and March $5^{\text {th }}$ of 2017 . In this study, the job to analyze the speech focused on the post of a young woman, which describes an act of violence and harassment suffered by her in a Carnival group (bloco) in São Paulo. In the analysis, it was observed how the internet user, on denouncing the violence act online and on responding to the comments of her publication, presents herself as a woman-victim, nonetheless empowered, acting in the activism against gendered violence online. The numbers contradict the idea that the violence against women must rest restricted as private matter, not appearing in a public and politic debate. We consider the technology as a practice of sociopolitical action (Moita Lopes, 2010), through which subpolitics turn up as escape lines for traditional politics, making circulate alternatives to fundamentalist ideas and practices
\end{abstract}

Keywords: Violence against women. Ciberactivism. Web 2.0. Gendered activism. 


\section{INTRODUÇÂO}

A contemporaneidade é marcada por consideráveis mudanças e transformações provenientes, principalmente, das alterações provocadas pelo avanço das tecnologias de informação e comunicação. No que se refere às relações humanas, esse fato traz consideráveis alterações no modo como os sujeitos se relacionam em sociedade e no modo como constroem suas subjetividades. As mudanças ocorridas em diversas esferas da comunicação humana vem sendo caracterizadas pelo conflito de identidades, ou, como bem definiu Stuart Hall (2003), pela "crise de identidade". A chamada crise de identidade coloca em foco $o$ descentramento do sujeito, frente às perdas dos referenciais da modernidade. Uma das consequências desse descentramento, segundo Hall (2003), foi o aparecimento das chamadas identidades híbridas, que emergem no lugar de uma subjetividade nacional e resistente ao processo de globalização. São identidades das culturas híbridas, do contato e da efemeridade das relações globais.

Diante desse cenário, o artigo busca refletir sobre a atual função do ciberespaço, tendo em vista o movimento de descentramento provocado pela vida em rede. Em especial, trataremos aqui do modo como o ciberespaço tornou-se, pelas consequências da globalização atual, um ambiente para a atuação política de gênero na contemporaneidade.
Um espaço que, em face de sua configuração como lugar de circulação de informação, possibilita a produção e veiculação de diferentes narrativas e vozes sociais. Nesse sentido, argumenta-se que as mídias digitais e as tecnologias de comunicação aumentaram as possibilidades e expectativas para mudanças no modo como as pessoas vêm construindo sua atuação política na sociedade, nas mais diversas esferas de atuação humana. $\mathrm{O}$ uso intensivo das redes virtuais apresenta-se como ferramenta de construção e desconstrução de significados para os indivíduos/usuários, em especial, a produção de lutas políticas e sociais.

Com base no que foi dito, nosso olhar volta-se para o modo como as plataformas digitais podem se tornar instrumentos para denúncias e construção da ação política contra violência de gênero. $\mathrm{O}$ corpus da pesquisa foi composto por denúncias feitas por mulheres no Facebook entre os dias 18 de fevereiro e 05 de março de 2017. O trabalho em análise focalizou o post de uma jovem, que relata um ato de violência e assédio sofrido por ela em um bloco de carnaval em São Paulo.

Antes de passarmos à análise, nas próximas seções, discutiremos aspectos da violência de gênero em nossa sociedade. Tomamos também a tecnologia como prática de ação sociopolítica (Moita Lopes, 2010), por meio da qual sub-políticas aparecem como linhas de fuga da política tradicional. 


\section{VIOLÊNCIA DE GÊNERO}

Compreender as relações de violência/assédio de gênero se mostra de forma ampla e direcionada assumir um papel de alta relevância e forte influência para as considerações e análises explicitadas nesta pesquisa. Averiguar informações e condutas ligadas às violências contra gênero, ocorridas nas esferas domésticas e/ou educacionais, segundo Carrara e Heibom (2009) possivelmente nos permitiria considerar e compreender as influências e ramificações presentes nas interações e comportamentos de inclinação agressiva por parte do público masculino. Ao ponderar sobre tais interações, devemos dar importância a construção e manutenção de alguns modelos de masculinidade, pois em grande parte

[...] desde a infância, há um modo de ser agressivo, de estímulo ao combate, à luta. Uma das formas principais de afirmação da masculinidade é por meio da força física, do uso do corpo como instrumento de luta para se defender, mas também para ferir. Como a violência é cultivada como valor masculino, muitas mulheres acabam submetidas a situações de sofrimento físico ou psíquico em razão da violência de seus companheiros, irmãos, pais, namorados, empregadores ou desconhecidos.

(CARRARA; HEIBOM, 2009, p. 74).

Fica evidente o quão complexo e árduo, porém necessário, é a promoção de discussões referentes às violências contra gênero. Mesmo demonstrando seu caráter duradouro, que se reforça e perdura ao decorrer dos anos, a estrutura de violência de gênero tem sido posta em visibilidade pela ideia/postura de conscientização e denúncia, como foi claramente aludido por Julio Wailselfisz (2015):

A violência contra a mulher não é um fato novo. Pelo contrário, é tão antigo quanto a humanidade. O que é novo, e muito recente, é a preocupação com a superação dessa violência como condição necessária para a construção de nossa humanidade. E mais novo ainda é a judicialização do problema, entendendo a judicialização como a criminalização da violência contra as mulheres, não só pela letra das normas ou leis, mas também, e fundamentalmente, pela consolidação de estruturas específicas, mediante as quais o aparelho policial e/ou jurídico pode ser mobilizado para proteger as vítimas e/ou punir os agressores.

(WAILSELFISZ, 2015, p. 7).

Examinar dados como os explícitos aqui, expressa a natureza ainda conflituosa e fatigante das questões de gênero em sociedade. Isso porque, além de estarem relacionadas aos altos índices de violências e assédios em si, acomete, inclusive, questões de ordem judicial, e/ou de políticas públicas, pois:

quando o Estado não responsabiliza os autores de atos de violência e a sociedade tolera, expressa ou tacitamente, tal violência, a impunidade não só estimula novos abusos, como também transmite a mensagem de 
que a violência masculina contra a mulher é aceitável, ou normal. O resultado dessa impunidade não consiste unicamente na denegação da justiça às diferentes vítimas/sobreviventes, mas também no fortalecimento das relações de gênero reinantes, e reproduz, além disso, as desigualdades que afetam as demais mulheres e meninas. (ONU, 2006 apud BRASIL, 2006, p.16).

Por fim, além de considerar tais estudos, devemos refletir sobre as formas de denúncia e as mudanças advindas de movimentos sociais e da luta individual de mulheres em situação de violência e abuso. Essa que se emerge partilhada por uma conjuntura "perversa da superioridade de gênero e geracional (homens mais velhos) manifesta nas atitudes violentas de pais, padrastos, tios" (CARRARA; HEIBOM 2009, p. 74). Dessa forma, possibilitando:

submeter milhares de meninas e moças a abusos de ordens diversas, sexuais (incestos, estupros) ou não, às vezes com a complacência de outras mulheres, inclusive suas mães, que em geral não conheceram outra perspectiva de vida que não fosse a da exploração social e sexual masculina. Assim, forja-se o chamado "pacto do silêncio" que submete, às vezes por longos anos, crianças e jovens, em especial as meninas, a situações de violência física, sexual e psicológica, com pesados danos para a sua saúde e integridade. (CARRARA; HEIBOM 2009, p. 7475).
Tal como vimos, a violência contra gênero se mostra, uma pauta, cada vez mais urgente e indiscutivelmente necessária. Em ações preventivas, e pela busca por soluções imediatas, pois fica evidente o impacto danoso para vítimas e pessoas envolvidas. Tanto em esfera individual e direcionada, como em análise coletiva e ampla, conforme alertado por Carrara e Heibom (2009, p. 74).

\section{O CIBERESPAÇO COMO LUGAR DE ATIVISMO POLITICO}

Bauman (2011, p. 35), utilizando a análise do sociólogo francês Alain Ehremberg sobre a declaração de Vivienne, na década de 1980, quando a jovem relata num programa popular de televisão da época, como a ejaculação precoce do seu marido a impossibilitava de chegar ao orgasmo, tal recorte elucida sobre o tornar público um determinado tipo de informação considerada, até então, estritamente do campo privado. Com esse exemplo, Bauman (2011), em sua reflexão sobre a modernidade líquida, discute sobre a passagem do privado para o público, no uso de uma ferramenta pública para expressar e discutir algo do foro íntimo. Atualmente isso está relacionado com as tecnologias de interações virtuais, que penetram e afetam as movimentações sociais e interferem também nas atividades políticas. Isso porque, segundo Sábado e Gordo (2008 apud MOITA LOPES, 2010, p.17), utilizamos a tecnologia para promover e estimular mudanças sociais.

Em face disso, revela-se pertinente e necessário examinar as modificações na maneira como as pessoas vem se relacionando e fazendo uso das ferramentas virtuais com objetivo de 
transgredir e ressignificar questões sociais e políticas. Ilustrativo desse momento é o fenômeno chamado ciberativismo. Como esclarecido por Sérgio da Silveira (2010 p. 15), o ciberativismo refere-se à possibilidade de dominar um amplo conjunto de práticas, orientadas em defesa das questões políticas, socioambientais e culturais realizadas nas redes virtuais.

Em direção semelhante, Moita Lopes (2010) faz alusão às ágoras na antiguidade e aos moinhos medievais em associação aos novos movimentos das mídias digitais, uma vez que tais espaços se constroem como um lugar favorável na troca e difusão de conhecimentos. As novas tecnologias de informação e comunicação atuam em diferentes esferas da vida pública e privada. Esse movimento de debate, ilustrado na ideia de àgora ou dos moinhos medievais, é típico da chamada Web. 2.0. Lankshear e Knobel (2007 apud MOITA LOPES, 2010) chama de web 2.0 as novas formas de se comunicar em rede. No espaço da web 2.0 os internautas compartilham uma postura colaborativa e produtora de conteúdos, favorecendo diferentes olhares e vozes sociais. Nessa compreensão, a Web 2.0 difere da Web 1.0 por ser regida pela lógica da participação e colaboração entre usuários, na qual predomina a possibilidade de integração entre produtores de conteúdo e consumidores (MOITA LOPES, 2010).

A conclusão a que se chega é a de que as ferramentas de comunicação virtual tornaram-se poderosos instrumentos de transformação nas esferas pública e privada. São instrumentos não apenas de informações, mas também legitimadores de pautas e agendas coletivas até então restritas ao âmbito da política tradicional.

\section{METODOLOGIA E CONTEXTO DE PESQUISA}

A metodologia de pesquisa que ancorou nossa pesquisa é de natureza interpretativista (MOITA LOPES, 1994). Nessa perspectiva, o significado deixa de ser resultado da intenção individual e passa a ser compreendido como uma construção coletiva. Situamos ainda esta investigação como um estudo de sabor etnográfico. Visto que este tipo de pesquisa

$\begin{array}{lr}\text { [...] procura descrever um } \\ \text { conjunto } & \text { de } \\ \text { entendimentos } & \text { e } \\ \text { conhecimentos } & \\ \text { específicos } & \\ \text { compartilhados } & \text { entre } \\ \text { participantes } & \text { que } \\ \text { conduzem } & \text { seu } \\ \text { comportamento } & \text { num } \\ \text { determinado } & \text { contexto. } \\ \text { (RODRIGUES, 2007, p. } \\ \text { 688). }\end{array}$

O corpus da pesquisa está centrado em denúncias feitas por mulheres no Facebook entre os dias 18 de fevereiro e 05 de março do ano 2017. Os dados foram gerados através da observação e gravação das interações em diferentes sites e rede social. Os instrumentos de geração de dados foram observação participante e a gravação das interações on-line, por captura de tela.

\section{ANÁLISE DA NARRATIVA/POST NA PÁGINA DO FACEBOOK}

O relato apresentado a seguir é público e viralizou na rede virtual do Facebook, no período do carnaval de 2017. A internauta que realiza o relato identifica-se em sua página 
pessoal como Carolina. Tendo em vista o fato de que relato é público dado e a proporção tomada, optamos por não apagar as identificações da internauta.

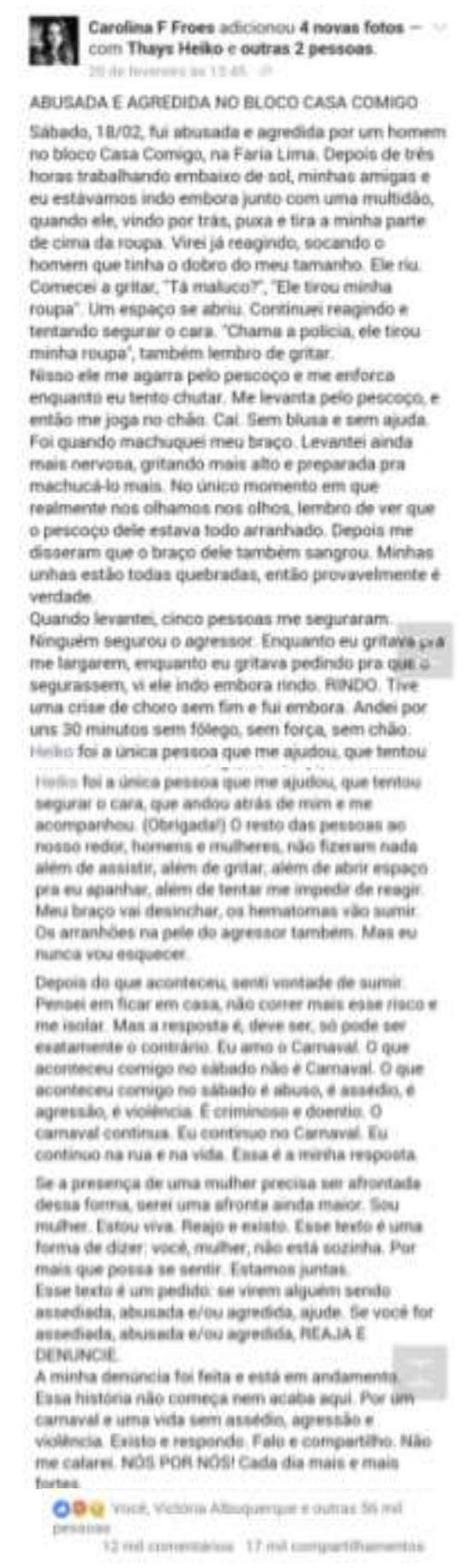

O carnaval pode ser entendido como uma temporada festiva que provoca entusiasmo e estimula euforia entre os brasileiros. Porém, a partir do relato exibido, revela-se outra versão. Esta sendo ainda mais comum no evento festivo: a violência e o assédio presente nas diversas interações do público frequentador do Carnaval.

A jovem internauta inicia seu relato dizendo que foi agredida e abusada em um bloco de carnaval, enquanto estava trabalhando ("Sábado, 18/02, fui abusada por um homem no bloco Casa Comigo, na Faria Lima. Depois de três horas trabalhando embaixo de sol"). Esse tipo de apresentação insere o evento de assédio no momento em que ela estava exercendo seu ofício. Tal modo de construir e apresentar a narrativa pode ser analisado como uma forma de legitimar seu relato, afastando a possibilidade de comentários de cunho questionador, comumente, utilizados para desvalidar narrativas desse teor, tendo em vista, o senso comum de que mulher no carnaval procura por situações de abuso ou assédio sexual.

Ainda é possível examinar ao final do relato, que a jovem além de expor sua experiência, também incentiva mulheres/meninas nesta situação a reagirem ("Se a presença de uma mulher precisa ser afrontada dessa forma, serei uma afronta ainda maior. Sou mulher. Estou viva. Reajo e existo. Este texto é uma forma de dizer: você, mulher, não está sozinha. Por mais que possa sentir. Estamos juntas. Esse texto é um pedido: se virem alguém sendo assediada, abusada e/ou agredida, ajude. Se for assediada, abusada e/ou agredida, REAJA E DENUNCIE").

Sua voz proporciona referências e afeta um coletivo feminino que até então, pelo "pacto do silêncio", era calado pelas normas e padrões do poder dominante. Ao reagir no momento da agressão, ela se constrói como um sujeito integrante de um feminino denunciante. Sem medo de falar ou expor a violência sofrida. Sua 
fala reverbera uma voz social, podendo provocar novas referências e reflexões para interações entre seus pares. Em seu post, a jovem atua no ativismo contra violência de gênero, promovendo o empoderamento e a expansão das possibilidades de reação, tanto para as pessoas afetadas, quanto para os possíveis espectadores.

Por fim, deve-se também refletir sobre o contexto no qual a narrativa/relato foi vinculado: uma página pessoal do Facebook, tendo em vista que o mesmo viralizou, gerando inúmeros comentários. A proporção alcançada pelo post da jovem foi de suma valia e interesse para a pesquisa desenvolvida, pois, como observado anteriormente sobre a Web 2.0, todos os usuários das mídias virtuais são integrantes de uma macroesfera na construção de um conhecimento coletivo. São também influenciados como um produtor de informações, conhecimentos, entretenimento e, nessa perspectiva, um potencial atuante no campo de discussões, reflexões e críticas. Dessa forma, através da plataforma virtual do Facebook, a internauta pôde interferir nas discussões e análises sobre violência e assédio no Carnaval.

\section{CONSIDERAÇÕES FINAIS}

Ao longo da referida pesquisa, revelouse indispensável ressaltar a percepção crítica que as interações virtuais podem fazer emergir. Considerando a postura participante presente na web 2.0, que são lugares sociais em que podemos reproduzir definições e padrões sociais dominantes, assim como também é um lugar propício para contestá-los, como bem mostramos no post utilizado para análise neste estudo. Ficou evidente o quanto os/as jovens da contemporaneidade podem estar mais inclinados e dispostos a participarem ativamente no campo das discussões sociais, até pouco tempo atrás restrita à política tradicional. $\mathrm{O}$ debate sobre a violência de gênero é um exemplo da passagem do nublado foro privado para o âmbito das reflexões públicas.

Devemos salientar como as diferentes formas de ativismo contra violência de gênero têm sido intensamente afetado e utilizado para legitimar e reverberar os relatos/discursos, inspirando e promovendo alternativas e ações denunciantes para um coletivo afetado pela lógica do "pacto do silêncio". O que implica também em promover reações que mobilizam terceiros. Como inspirar redes de apoio às vítimas, campanha de conscientização sobre a violência no Carnaval, entre outros.

Portanto, torna-se indispensável explicitar e promulgar incentivos nos atos de denúncia contra as violências/assédios. Especialmente, relatos realizados pelas próprias vítimas e por membros integrantes do convívio da mesma, ou até por parte de profissionais que percebam suspeitas quanto à ocorrência de violências. A denúncia é uma defesa importante na luta contra as violências de gênero, visto que, além de impactar sobre outras vítimas, viabiliza possibilidades de intervenção, cuidados e acolhimento para as vítimas, como para membros envolvidos, como apontou De Almeida Ferrari e Vecine (2002).

\section{AGRADECIMENTOS}

Agradecemos à Universidade Vale do Rio Verde e ao Programa de Mestrado em Letras 
pela bolsa de Iniciação Científica, sem a qual esta pesquisa não poderia ter sido realizada.

\section{REFERÊNCIAS}

BAUMAN, Z. 44 Cartas do Mundo Líquido Moderno. Rio de Janeiro: Jorge Zahar Editor, 2011.

BRASIL. Ministério das Mulheres, da Igualdade Racial, da Juventude e dos Direitos Humanos. Diretrizes nacionais feminicídio. Investigar, processar e julgar com perspectiva de gênero as mortes violentas de mulheres. Brasília, 2016.

CARRARA, Sergio; HEIBOM, Maria Luiza. Gênero e diversidade na escola: formação de professoras/es em Gênero, Orientação Sexual e Relações ÉtnicoRaciais. Caderno de Atividades. Rio de Janeiro/Brasília: CEPESC/SPM, 2009.

DA SILVEIRA, Sérgio Amadeu. Ciberativismo, cultura hacker e o individualismo colaborativo. Revista Usp, n. 86, 2010.

DE ALMEIDA FERRARI, Dalka Chaves; VECINA, Tereza Cristina Cruz. O fim do silêncio na violência familiar: teoria e prática. ed. Agora, 2002. Disponível em: <http://www.spm.gov.br/central-deconteudos/publicacoes/2016/livro-diretrizesnacionais-femenicidios-versao-web.pdf $>$. Acesso em 29 de ago. 2017.

HALL, S. A identidade cultural na pós-modernidade. Trad. Tomaz Tadeu da Silva e Guacira Lopes Louro. 7.ed. Rio de Janeiro: DP\&A, 2003.

MOITA LOPES, L.P. Os novos letramentos digitais como lugares de construção de ativismo político sobre sexualidade e gênero. Trab. Ling. Aplic., Campinas, v.49, n 2, p. 393-417, Jul./Dez. 2010.

MOITA LOPES, L.P. Pesquisa Interpretativista em Linguística Aplicada: a Linguagem como condição e Solução, DELTA, 10 (2), p.329-338, 1994.

RODRIGUES, William Costa. Metodologia Científica. ed. Paper Vest, 2007.

WAILSELFISZ, J. J. Mapa da violência 2015: homicídios de mulheres no Brasil. FLACSO Brasil: Brasília, 2015. Disponível em: <http://www.mapadaviolencia.org.br/pdf2015/MapaVi olencia 2015 mulheres.pdf $>$. Acesso em 27 de ago. 2017.

Domynique Roberta de Oliveira Esposito
Bolsista de Iniciação Científica do Programa de
Mestrado em Letras da UninCor. Discente da
Graduação em Psicologia da UninCor.

Thayse Figueira Guimarães
Professora da graduação e do Programa de Pós-
Graduação em Letras da Universidade Vale do Rio
Verde de Três Corações - UninCor. É doutora em
Linguística Aplicada pelo Programa Interdisciplinar
em Linguística Aplicada da Universidade Federal do
Rio de Janeiro (2014).

